\title{
Photodynamic therapy of malignant glioma with hypericin: Comprehensive in vitro study in human glioblastoma cell lines
}

\author{
RAINER RITZ ${ }^{1}$, HANNAH T. WEIN $^{1}$, KLAUS DIETZ ${ }^{2}$, MARTIN SCHENK ${ }^{3}$, \\ FLORIAN ROSER $^{1}$, MARCOS TATAGIBA ${ }^{1}$ and WOLFGANG S.L. STRAUSS ${ }^{4}$
}

\author{
Departments of ${ }^{1}$ Neurosurgery, ${ }^{2}$ Medical Biometry, and ${ }^{3}$ Surgery, Eberhard-Karls-Universität Tübingen, Tübingen \\ ${ }^{4}$ Institut für Lasertechnologien in der Medizin und Messtechnik an der Universität Ulm, Ulm, Germany
}

Received September 15, 2006; Accepted November 3, 2006

\begin{abstract}
The poor prognosis of patients suffering from malignant glioma requires further efforts. Photodynamic therapy (PDT) might be a therapeutic option to increase surgical radicality. Hypericin (HY) exhibit high phototoxicity to malignant cells and accumulates to a higher extent in glioblastoma cells as compared to neurons. Therefore, the impact of various experimental parameters on cytotoxicity, intracellular accumulation and phototoxicity of HY was quantitatively assessed in the three human glioblastoma cell lines U373 MG, LN229 and T98G. Additionally, intracellular location of HY was studied with fluorescence microscopic techniques. For all three cell lines, no cytotoxicity was found for incubation concentrations up to $5 \mu \mathrm{M}$. For short-time incubation ( $2 \mathrm{~h}$ ), maximum HY fluorescence was achieved at an incubation concentration of about $5 \mu \mathrm{M}$. However, uptake kinetics of HY was dependent on its incubation concentration. Moreover, increase in HY fluorescence was negligible at $4^{\circ} \mathrm{C}$, which strongly indicates that the compound is taken up by an energy-dependent process. HY exhibited high phototoxicity (at $595 \mathrm{~nm}$ ) in all three cell lines with $\mathrm{ID}_{50}$-values ranging from $0.15 \mathrm{~J} / \mathrm{cm}^{2}$ to $0.22 \mathrm{~J} / \mathrm{cm}^{2}$, but sensitivity decreased in the order U373 MG > LN229 > T98G. However, assessment of phototoxicity at different wavelengths revealed that highest cell inactivation was achieved at $600 \mathrm{~nm}$. Fluorescence microscopy showed that HY fluorescence arose predominantly from the perinuclear region and the nuclear membrane. Fluorescence pattern of HY was significantly different from those observed for organelle markers staining lysosomes or mitochondria. Location of HY in the plasma membrane was proven by total internal reflection fluorescence microscopy. Thus, the present study demonstrates that glioblastoma cells can be effectively
\end{abstract}

Correspondence to: Dr Rainer Ritz, Department of Neurosurgery, Eberhard-Karls-Universität Tübingen, Hoppe-Seyler-Str. 3, D-72076 Tübingen, Germany

E-mail: rainer.ritz@med.uni-tuebingen.de

Key words: hypericin, photodynamic therapy, glioblastoma cells inactivated by HY-PDT after short-time incubation and exposure to low light doses. These results obtained in cell culture are encouraging and justify further evaluation HY-PDT for the treatment of malignant glioma in animal experiments.

\section{Introduction}

Photodynamic therapy (PDT) is a relatively new modality of cancer treatment, which rely on the administration of a photosensitizer, which preferentially accumulates in tumour tissue. Upon illumination at the appropriate wavelength the photosensitizer molecules are excited from their ground state $S_{0}$ to an electronically excited singlet state $S_{x}$. The excited state energy can be dissipated via several competing relaxation pathways. Transition of the photosensitizer molecules from the lowest excited singlet state $S_{1}$ to the lowest triplet excited state $\mathrm{T}_{1}$ (intersystem crossing) is required for the generation of cytotoxic reactive oxygen species (ROS). Superoxide radicals result from several electron transfer reactions (type I mechanism), whereas singlet oxygen is generated by energy transfer from triplet state molecules to molecular oxygen (type II mechanism). ROS react with various biomolecules (e.g. proteins) causing tumour cell death (1).

Hypericin (HY), a phenanthroperylene quinone, is a naturally occuring compound found in plants of the genus Hypericum, of which Hypericum perforatum (St. John's wort) is most common. Besides pharmacological activity in the dark, e.g. antiviral (2), antitumoral (3) and antiangiogenetic activity (4), HY exhibit excellent photosensitizing properties [reviewed by Agostinis et al (5)], mainly due to its high triplet quantum yield and its efficient generation of ROS $(6,7)$. Consequently, phototoxicity of HY was diminished when specific quenchers of ROS were applied (8) or under hypoxic conditions (9). HY-mediated photodynamic inactivation of malignant cell lines of different origin (9-15), including glioblastoma cells $(16,17)$, has been demonstrated during the last decade.

Patients suffering from malignant glioma have a very poor prognosis. Although median survival of patients treated with surgery, radiation and chemotherapy has been prolonged during the last few years $(18,19)$, many patients die within the first year after diagnosis. Recurrence of malignant glioma occurs most frequently at the margins of resection (20). 
Surgical radicality was successfully improved by fluorescence-guided resection of the tumours after administration of 5-aminolaevulinic acid (5-ALA) $(21,22)$. This intermediate of porphyrin biosynthesis is converted to protoporphyrin IX (PP IX) in most cell types. Quite selective accumulation of 5ALA-induced PP IX has been demonstrated for malignant glioma cells in vitro $(23,24)$ and in vivo $(25,26)$ as well as for many other tumour cells. In addition, due to the photosensitizing properties of PP IX, photodynamic treatment of malignant glioma might be considered as a promising additional therapeutic option, which is currently investigated in vitro $(27,28)$ and in vivo $(29-32)$.

In particular, the observation that HY accumulates to a higher extent in glioblastoma cells as compared to neurons (33) recommends a comprehensive evaluation of the sensitivity of glioblastoma cells to HY-PDT. Thus, the objective of the present study was to investigate the impact of various experimental parameters, e.g. photosensitizer concentration or incubation time, on cytotoxicity, intracellular accumulation and phototoxicity of HY in three human glioblastoma cell lines. In addition, intracellular location of HY was studied with different fluorescence microscopic techniques.

\section{Materials and methods}

Chemicals. Hypericin (HY) was obtained from Phytochem (Ichenhausen, Germany) with a purity higher than $99 \%$. Stock solutions of $\mathrm{HY}$ were made up in DMSO at a concentration of $2 \mathrm{mM}$ and stored in the dark at $-20^{\circ} \mathrm{C}$. For all experiments, incubation media were freshly prepared in cell culture medium (at a final FCS content of $10 \%$; see below) under sterile conditions.

Cell cultivation. Human glioblastoma cell lines were obtained from either the European Collection of Cell Cultures, Wiltshire, UK (U373 MG cells, ECACC No. 890811403) or from the American Type Culture Collection, Manassas, VA, USA (LN229, ATCC No. CRL-2611; T89G, ATCC No. CRL-1690). All three cell lines were routinely grown in RPMI-1640 medium (Gibco-BRL, Paisley, UK; supplemented with GlutaMAX ${ }^{\mathrm{TM}}$ ) supplemented with 10\% FCS (Biochrom, Berlin, Germany) and antibiotics [penicillin (100 IU/ml) and streptomycin $(100 \mu \mathrm{g} / \mathrm{ml})$; Gibco-BRL] maintained at $37^{\circ} \mathrm{C}$ and $5 \%$ carbon dioxide in an incubator (Cellstar; Nunc, Wiesbaden, Germany). Cells were detached by incubation with Accutase ${ }^{\mathrm{TM}}$ (PAA Laboratories, Pasching, Austria) at $37^{\circ} \mathrm{C}$ for 5-10 min after rinsing with phosphate-buffered saline (PBS, Gibco-BRL). For all experiments, cells were seeded at a defined density of 150 cells $/ \mathrm{mm}^{2}$ and grown at same conditions for $24 \mathrm{~h}$ prior to incubation.

Cytotoxicity. To determine cytotoxity of HY, cells were grown in 24-well plates (Nunc; seeding of $3 \times 10^{4}$ cells/well) and incubated $\left(37^{\circ} \mathrm{C}\right)$ with $\mathrm{HY}$ at concentrations of 0.5 , $1.0,2.5,5$ and $10 \mu \mathrm{M}$ for $2 \mathrm{~h}$ or $24 \mathrm{~h}$. After rinsing with PBS cells were reincubated with (photosensitizer-free) culture medium and grown for $48 \mathrm{~h}\left(37^{\circ} \mathrm{C} / 5 \% \mathrm{CO}_{2}\right)$. Cell survival was assessed with the neutral red (NR) assay $(10,34)$. Cultures were thus incubated $\left(37^{\circ} \mathrm{C}\right)$ with an aqueous NR solution [Biochrom; diluted with culture medium 1:25
$(\mathrm{V} / \mathrm{V})$ resulting in final NR concentration of $0.012 \%$ and adjusted to $\mathrm{pH} 7.4]$ for 2-3 h (by addition of $500 \mu 1 \mathrm{NR}$ solution to each well). Supernatants were discarded and cells were rinsed twice with isotone saline. Neutral red was extracted from the cells by addition of $150 \mu 1$ of a mixture of water/ethanol/acetic acid (1/1/0.02, V/V/V). After gentle agitation for $10 \mathrm{~min}$, a $100 \mu \mathrm{l}$ aliquot of each sample was transferred into a microtiter plate (Greiner, Frickenhausen, Germany). Absorbance was measured at $570 \mathrm{~nm}$ (with a reference wavelength of $690 \mathrm{~nm}$ ) on a plate reader (Lucy 1, anthos Mikrosysteme, Krefeld, Germany) and analysed with the anthos WinRead Software (Version 2.3). Cell survivals were calculated as percentages of the non-incubated controls. For each cell line, at least three independent experiments were performed in quadruplicate.

Phototoxicity. To determine phototoxicity of HY, cells were cultured in 4-well plates (Nunc; seeding of $3 \times 10^{4}$ cells/ well) and incubated $\left(37^{\circ} \mathrm{C}\right)$ with $\mathrm{HY}$ at a non-cytotoxic concentration of $2.5 \mu \mathrm{M}$ for $2 \mathrm{~h}$. After rinsing with PBS and reincubation with culture medium (without photosensitizer) cells were illuminated using a dye laser (model 375, Spectra Physics, Mountain View, USA) pumped by an argon ion laser (model 2030, Spectra Physics). All three cell lines were illuminated with energy densities (light doses) of $0.05,0.1$, $0.15,0.2,0.25,0.3,0.4$ and $0.5 \mathrm{~J} / \mathrm{cm}^{2}$ at $595 \mathrm{~nm}$ (12) and a power density (fluence rate) of $5 \mathrm{~mW} / \mathrm{cm}^{2}$ by increasing exposure times from $10 \mathrm{sec}$ to $100 \mathrm{sec}$. Photodynamic inactivation of T98G and U373 MG cells was also determined for various incubation concentrations of $\mathrm{HY}(0.1-2.5 \mu \mathrm{M} / 2 \mathrm{~h} /$ $\left.37^{\circ} \mathrm{C}\right)$. Cells were illuminated with energy densities of up to $1.5 \mathrm{~J} / \mathrm{cm}^{2}$ at $595 \mathrm{~nm}\left(5-10 \mathrm{~mW} / \mathrm{cm}^{2}\right)$ as described above. In addition, LN229 cells were illuminated at different wavelengths ranging from $575 \mathrm{~nm}$ to $615 \mathrm{~nm}$ (in $5 \mathrm{~nm}$ steps). For each wavelength, the light was delivered at a power density of $10 \mathrm{~mW} / \mathrm{cm}^{2}$ and cells were exposed for $30 \mathrm{sec}$ (corresponding to an energy density of $0.3 \mathrm{~J} / \mathrm{cm}^{2}$ ).

All illumination experiments were monitored with a power meter (model TPM-310, Gentec, Quebec, Canada). In each case, cell survival was assessed photometrically using the NR assay (as described above) after an additional growth period of $48 \mathrm{~h}\left(37^{\circ} \mathrm{C}, 5 \% \mathrm{CO}_{2}\right)$. Cell survivals were calculated as percentages of the incubated and non-illuminated controls. As a quantitative measure of phototoxicity, $\mathrm{ID}_{50}$-values [inactivation doses (light doses) required to reduce cell survival to $50 \%$ of the controls] were deduced from dose response curves. In each case, at least three independent experiments were performed in quadruplicate.

Intracellular accumulation. To determine the kinetics of intracellular accumulation of HY, U373 MG cells were cultivated in 24-well plates (seeding of $3 \times 10^{4}$ cells/well) and incubated $\left(37^{\circ} \mathrm{C}\right)$ with either different HY concentrations $(0.5,1.0,1.5,2.0,2.5,5,10,15$ and $20 \mu \mathrm{M})$ for $2 \mathrm{~h}$ or different incubation times $(5,10,15,30 \mathrm{~min}$ and 1.5, 2, 3, 4, 6 and $24 \mathrm{~h}$ ) at $\mathrm{HY}$ concentrations of $2.5,5$ and $20 \mu \mathrm{M}$. After rinsing with PBS $(500 \mu 1)$ cells were detached with Accutase $^{\mathrm{TM}}$ (300 $\mu 1$ as described above). Cells of 4 identically treated wells were pooled and filtered using a metal mesh (100-112 $\mu \mathrm{m}$ pore size; Haver \& Boecker, Oelde, Germany). 
After addition of propidium iodide (Sigma-Aldrich, Steinheim, Germany) dissolved in PBS $(2 \mathrm{mg} / \mathrm{ml} ; 10 \mu \mathrm{l}$ per $1 \mathrm{ml}$ cell suspension) fluorescence of HY-treated cells was measured by flow cytometry (FACSSORT, Becton-Dickinson, San Jose CA, USA; excitation wavelength: $488 \mathrm{~nm}$ ). Measurements were done considering the parameters forward scatter (FSc) and side scatter (SSc) to identify the cell population (dot plot FSc vs. SSc), fluorescence channel 2 (FL2, emission wavelength: $585 \pm 21 \mathrm{~nm}$ ) to determine cellular HY uptake and fluorescence channel 3 (FL3, emission wavelength: $>670 \mathrm{~nm}$ ) to assess cell viability and analysed with the CellQuest $^{\mathrm{TM}}$ software (version 4.0.2, Becton-Dickinson). In each case, at least 4 independent experiments were performed in duplicate and each data point represents the mean fluorescence intensity of 25.000 cells. To study the uptake mechanism of HY, U373 MG cells were cultivated in 24well plates. After pre-cooling of cells and incubation medium at $4^{\circ} \mathrm{C}$ for $1 \mathrm{~h}$, cells were incubated with $2.5 \mu \mathrm{M} \mathrm{HY}$ at $4^{\circ} \mathrm{C}$ for $2 \mathrm{~h}$ and subsequently at $37^{\circ} \mathrm{C}$ for another $2 \mathrm{~h}$. Cells concomitantly incubated with $\mathrm{HY}(2.5 \mu \mathrm{M} /$ without precooling of the medium) at $37^{\circ} \mathrm{C}$ for $4 \mathrm{~h}$ served as controls. After rinsing the cultures with PBS and detachment of the cells with Accutase ${ }^{\mathrm{TM}}$ intracellular accumulation of HY was determined by flow cytometry as described above.

Intracellular location. To determine the intracellular location of HY, cells were cultivated on object slides (Marienfeld, Lauda-Königshofen, Germany; seeding of $2.85 \times 10^{5}$ cells/ slide) and incubated $\left(37^{\circ} \mathrm{C}\right)$ with $\mathrm{HY}$ at concentrations of 0.5 , 1.5 and $2.5 \mu \mathrm{M}$ for $2 \mathrm{~h}$. In addition, cells were incubated with either the mitochondrial marker rhodamine 123 (R 123, Fluka, Buchs, Switzerland; $1 \mu \mathrm{M} / 1 \mathrm{~h}$ ) or the lysosomal marker acridine orange (AO, Molecular Probes, Eugene, USA; $1 \mu \mathrm{M} / 1 \mathrm{~h}$ ). In all cases, cells were rinsed with Earl's buffered salt solution (EBSS, Sigma-Aldrich) prior to fluorescence microscopy (Axioplan 1, Carl Zeiss Jena, Jena, Germany). Two different fluorescence microscopic techniques were applied: a) Conventional fluorescence microscopy \{light source: high pressure mercury lamp (HBO 50, Carl Zeiss) in combination with appropriate filters [band-pass filters at 510$560 \mathrm{~nm}(\mathrm{HY} / \mathrm{AO})$ and 450-490 nm (HY/R 123)] as well as dichroic mirrors [580 nm (HY/AO) and $510 \mathrm{~nm}(\mathrm{R} \mathrm{123)})$ \} was used to investigate the distribution of HY and the organelle markers within whole cells (epi-illumination). b) Total internal reflection fluorescence microscopy [TIRFM, light source: pulsed laser diode (LDH C470 with driver PDL 800-B, Picoquant, Berlin, Germany; wavelength: $470 \mathrm{~nm}$, repetition rate: $40 \mathrm{MHz}$, average power: $1.2 \mathrm{~mW}$ ) adapted to the fluorescence microscope using a single mode fiber (Point Source, Southampton, UK)] was applied to demonstrate HY location within the plasma membrane of glioblastoma cells (TIR illumination). In the second case, fluorescence is excited by an evanescent electromagnetic field (arising upon total internal reflection of the excitation laser light at the cell substrate interface) with a penetration depth $d(\Theta, \lambda)$ of about $100 \mathrm{~nm}$ (range between $70 \mathrm{~nm}$ and $250 \mathrm{~nm}$ depending on the angle of incidence $\Theta$ and the wavelength of the excitation light $\lambda$ ) enabling an almost selective examination of the plasma membrane (with quite little contribution of adjacent cellular sites). The variable angle TIRFM device used in this study has been described in detail previously (35). In all cases, fluorescence was detected using an EMCCD camera (with Peltier cooling, sensitivity below $10^{-17} \mathrm{~W} /$ Pixel; DV887DC-BV, ANDOR Technology, Belfast, UK) in combination with appropriate long-pass filters $[>590 \mathrm{~nm}$ (HY/AO) and >520 nm (R 123)].

Statistical analysis. Values of the quantitative data are given as median (central tendency) \pm median absolute deviation (MAD, variability) except otherwise noted.

The relation between incubation concentration of HY $c_{i}$ and cellular fluorescence $\mathrm{I}_{F}\left(c_{i}\right)$ was fitted by a non-linear least square estimation with 4 parameters according to:

$$
I_{F}\left(c_{i}\right)=I_{0}+\frac{I_{\max }-I_{0}}{1+\left(\frac{K_{50}}{c_{i}}\right)^{a}} \text { for } c_{i}>0
$$

with minimum intensity $I_{0}$ (a.u.) (i.e. cellular autofluorescence), maximum intensity $I_{\max }$ (a.u.), $K_{50}$-value $(\mu \mathrm{M})$ corresponding to $c_{i}(\mu \mathrm{M})$ resulting in half-maximal fluorescence as well as the fitting parameter $\alpha=1.5$.

For an incubation concentration of $2.5 \mu \mathrm{M}$, the relation between incubation time of HY $t$ and cellular fluorescence $I_{F}(t)$ was fitted according to:

$$
I_{F}(t)=\frac{v}{\alpha}\left(1-e^{-\alpha t}\right)
$$

with the two fitting parameters $v$ and $\alpha$ describing increase and decline of HY fluorescence, respectively.

For incubation concentrations of $10 \mu \mathrm{M}$ and $20 \mu \mathrm{M}$, the relation between incubation time of HY $t$ and cellular fluorescence $I_{F}(t)$ was fitted by a compartment model with 4 parameters according to:

$$
\begin{gathered}
I_{F}(t)=I_{\max }\left(1-\mathrm{e}^{\gamma t}\right), \text { for } t<t_{\max } \\
\left.I_{F}(t)=I_{\infty}+\left(I_{\max }\left(1-\mathrm{e}^{-\gamma t_{\max }}\right)-I_{\max }\right) \mathrm{e}^{-\alpha}\left(\mathrm{t}-\mathrm{t}_{\max }\right) \text { for } t \geq t_{\max } \text { iv }\right)
\end{gathered}
$$

with maximum intensity $I_{\max }$ (a.u.) achieved at the incubation time $t_{\max }(\mathrm{h})$ and $I_{\infty}$ (a.u.) corresponding to the intensity at infinite incubation time $t_{\infty}$ of HY. Parameters $\gamma$ and $\alpha$ are characterizing uptake of HY from the incubation medium into the cells (at short incubation times) and cellular release of HY into the medium (at longer incubation times), respectively.

Phototoxicity, i.e. the relation between cell survival and light doses, was fitted according to:

$$
S F=\frac{100}{1+\left(\frac{E}{I D_{50}}\right)^{a}}
$$

with surviving fraction $S F$ (\% of control), energy density $E$ $\left(\mathrm{J} / \mathrm{cm}^{2}\right)$, inactivation dose $I D_{50}\left(\mathrm{~J} / \mathrm{cm}^{2}\right)$ and a fitting parameter $a$.

For post-hoc pair-wise comparison the Tukey-Kramer HSD test was used. The global significance level was $5 \%$. All statistical calculations and curve fittings were carried out with the software package JMP version 5.1 (www.JMP.com). 

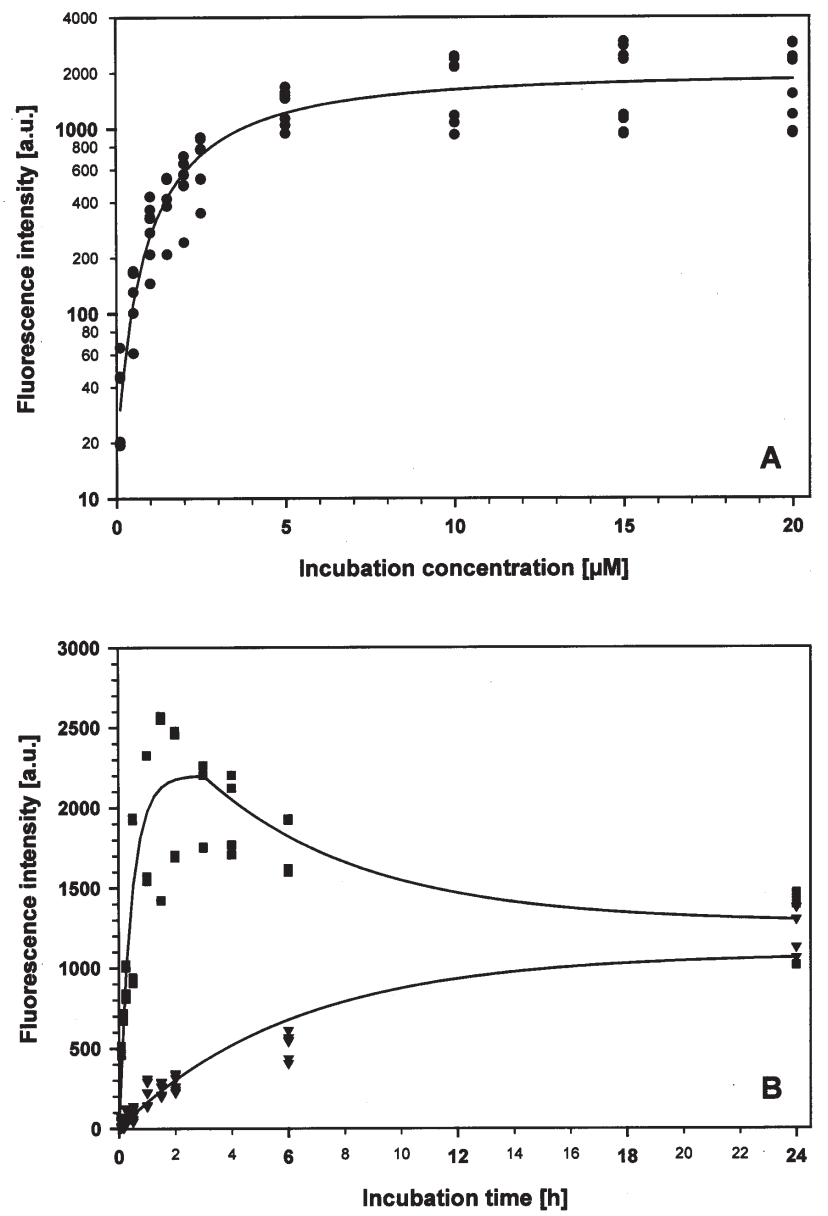

Figure 1. Cellular accumulation of hypericin in U373 MG glioblastoma cells dependent on (A) incubation concentration (incubation time of $2 \mathrm{~h}$ ) and (B) incubation time [incubation concentrations of $2.5 \mu \mathrm{M}(\mathbf{\nabla})$ and $20 \mu \mathrm{M}(\mathbf{(})$ ] measured by flow cytometry.

\section{Results}

Cytotoxicity. Cytotoxicity of HY was determined in the three human glioblastoma cell lines U373 MG, LN229 and T98G for two different incubation times. After short-time incubation of $2 \mathrm{~h}$ the photosensitizer exhibited no cytotoxicity (defined as $>95 \%$ viable cells as compared to non-incubated controls) up to an incubation concentration of $5 \mu \mathrm{M}$. Extremely weak cytotoxicty (cell survival $>90 \%$ of the controls) was found after increasing either the incubation concentration to $10 \mu \mathrm{M}$ or the incubation time to $24 \mathrm{~h}$. No significant differences between the three different cell lines were observed for any of the incubation conditions investigated.

Intracellular accumulation. U373 MG glioblastoma cells were selected as an example to study intracellular accumulation of HY in a time- and concentration-dependent manner by flow cytometry, i.e. cellular fluorescence served as a measure for intracellular HY accumulation. Cells were either incubated at HY concentrations up to $20 \mu \mathrm{M}$ for $2 \mathrm{~h}$ or at $\mathrm{HY}$ concentrations of $2.5,10$ or $20 \mu \mathrm{M}$ up to $24 \mathrm{~h}$. In each case, the fraction of viable cells within the samples was $>90 \%$ as determined by propidium iodide staining, although the highest incubation concentration of HY $(20 \mu \mathrm{M})$ was not considered in the cell-based assay for cytotoxicity (see above).

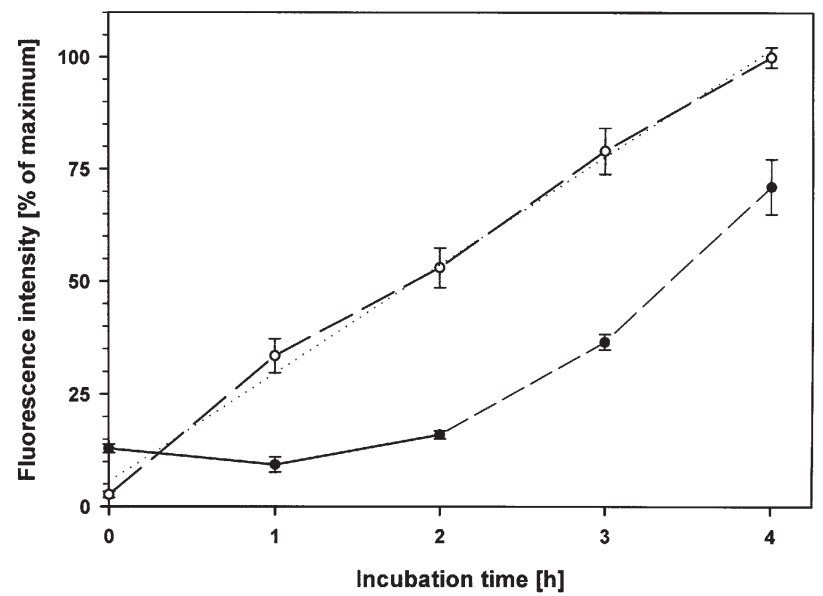

Figure 2. Cellular accumulation of hypericin in U373 MG glioblastoma cells (incubation concentration $2.5 \mu \mathrm{M}$ ) dependent on incubation temperature [ $4^{\circ} \mathrm{C}$ for $2 \mathrm{~h}$ and subsequently $37^{\circ} \mathrm{C}$ for further $2 \mathrm{~h}(\bullet)$ vs. $37^{\circ} \mathrm{C}$ for $4 \mathrm{~h}(\mathrm{o})$ ] measured by flow cytometry.

For short-time incubation of $2 \mathrm{~h}$, cellular fluorescence increased up to incubation concentrations of about $5 \mu \mathrm{M}$, whereas no further increase in HY accumulation was found at higher incubation concentrations. Measured values as well as the fitted curve (according to equation i) are shown in Fig. 1A.

After incubation of U373 MG cells with HY at a concentration of $2.5 \mu \mathrm{M}$ a continuous increase in cellular fluorescence was observed up to $6 \mathrm{~h}$. Extension of the incubation period up to $24 \mathrm{~h}$ resulted in further intracellular HY accumulation with a doubling of fluorescence intensity. In contrast, kinetics of cellular HY accumulation was significantly different at higher incubation concentrations of 10 and $20 \mu \mathrm{M}$. In both cases, the photosensitzer was rapidly taken up and highest intracellular accumulation was found after about $2 \mathrm{~h}$ incubation. In agreement with the results described above, maximum fluorescence intensities were quite similar for both HY concentrations. Increase in incubation time up to $6 \mathrm{~h}$ resulted in a lowering of cellular fluorescence by about $20-30 \%$ as compared to maximum fluorescence. After $24 \mathrm{~h}$ incubation cellular fluorescence was further reduced and intensity was in the same order of magnitude as attained for an incubation concentration of $2.5 \mu \mathrm{M}$. Measured values as well as the fitted curves [according to equation ii (2.5 $\mu \mathrm{M}$ incubation) and equations iii and iv (20 $\mu \mathrm{M}$ incubation)] are shown in Fig. 1B.

Cellular uptake mechanism. To study the mechanism of cellular HY uptake in more detail, U373 MG glioblastoma cells were incubated with HY $(2.5 \mu \mathrm{M})$ at different temperatures. Cellular HY accumulation was negligible in the first half of the incubation period at $4^{\circ} \mathrm{C}$, whereas cellular HY fluorescence increased rapidly when cells were subsequently incubated at $37^{\circ} \mathrm{C}$ for another $2 \mathrm{~h}$. At the end of the incubation period fluorescence intensity was about two-thirds of that found for control cells incubated at $37^{\circ} \mathrm{C}$ for $4 \mathrm{~h}$. These data are depicted in Fig. 2.

Phototoxicity. In first set of experiments, phototoxicity of HY was determined for all three glioblastoma cell lines 
Table I. Phototoxicity of HY in human glioblastoma cell lines (incubation: $2.5 \mu \mathrm{M}$ for $2 \mathrm{~h}$ ) after illumination at $595 \mathrm{~nm}$ $\left(5 \mathrm{~mW} / \mathrm{cm}^{2}\right)$.

\begin{tabular}{lc}
\hline Cell line & $\mathrm{ID}_{50}$-value $\left(\mathrm{J} / \mathrm{cm}^{2}\right)$ \\
\hline U373 MG & 0.15 \\
LN229 & 0.19 \\
T98G & 0.22 \\
\hline
\end{tabular}

Table II. Phototoxicity of HY in human T98G glioblastoma cells incubated at different concentrations $(2 \mathrm{~h})$ after illumination at $595 \mathrm{~nm}\left(10 \mathrm{~mW} / \mathrm{cm}^{2}\right)$.

\begin{tabular}{lc}
\hline HY concentration $(\mu \mathrm{mol})$ & $\mathrm{ID}_{50}$-value $\left(\mathrm{J} / \mathrm{cm}^{2}\right)$ \\
\hline 0.5 & 0.88 \\
1.5 & 0.34 \\
2.5 & 0.20 \\
\hline
\end{tabular}

U373 MG, LN229 and T89G at a non-cytotoxic incubation concentration of $2.5 \mu \mathrm{M}$ (incubation time of $2 \mathrm{~h}$ each) and an illumination wavelength of $595 \mathrm{~nm}$. Illumination of HY treated cells resulted in considerable reduction in cell viability and $\mathrm{ID}_{50}$-values of $0.15 \mathrm{~J} / \mathrm{cm}^{2}$ (U373 MG), $0.19 \mathrm{~J} / \mathrm{cm}^{2}$ (LN229) and $0.22 \mathrm{~J} / \mathrm{cm}^{2}$ (T98G) were calculated. The $\mathrm{ID}_{50}$-value for U373 MG cells was significantly different from that for T98G cells using one-way analysis (Tukey-Kramer test, $\mathrm{p}<0.05)$. These data are summarized in Table I. Exposure of the cell to $0.4 \mathrm{~J} / \mathrm{cm}^{2}$ resulted in a decrease in cell viability of about one order of magnitude and cell survival varied between $9 \%$ (U373 MG ) and 12-13\% (LN229 and T98G).

Subsequently, the relation between incubation concentration of HY and photodynamic inactivation of glioblastoma cells was studied in some more detail. Therefore, phototoxicity of HY was also determined for different non-cyctoxic concentrations in T98G and U373 MG cells at an illumination wavelength of $595 \mathrm{~nm}$. In case of T98G cells, complete dose-response curves were determined for incubation concentrations of $0.5,1.5$ and $2.5 \mu \mathrm{M}$ at incubation times of $2 \mathrm{~h}$ each. ID $_{50}$-values increased with decreasing HY concentration from $0.2 \mathrm{~J} / \mathrm{cm}^{2}(2.5 \mu \mathrm{M})$ over $0.34 \mathrm{~J} / \mathrm{cm}^{2}$ $(1.5 \mu \mathrm{M})$ to $0.88 \mathrm{~J} / \mathrm{cm}^{2}(0.5 \mu \mathrm{M})$. These data are summarized in Table II and dose-response curves are shown in Fig. 3A. In case of U373 MG cells, cultures were exposed to HY concentrations between $0.1 \mu \mathrm{M}$ and $2.5 \mu \mathrm{M}$ (incubation times of $2 \mathrm{~h}$ each) and equal light doses of $0.3 \mathrm{~J} / \mathrm{cm}^{2}$. Photodynamic treatment at incubation concentrations of up to $1 \mu \mathrm{M}$ resulted in weak to moderate cell inactivation $(>75 \%$ cell survival). In contrast, pronounced cell damage with survival rates of about $25 \%$ was observed at $\mathrm{HY}$ concentrations $\geq 1.5 \mu \mathrm{M}$ (Fig. 3B). These results indicate that no simple relation exists between photodynamic efficacy of $\mathrm{HY}$ and its incubation concentration.
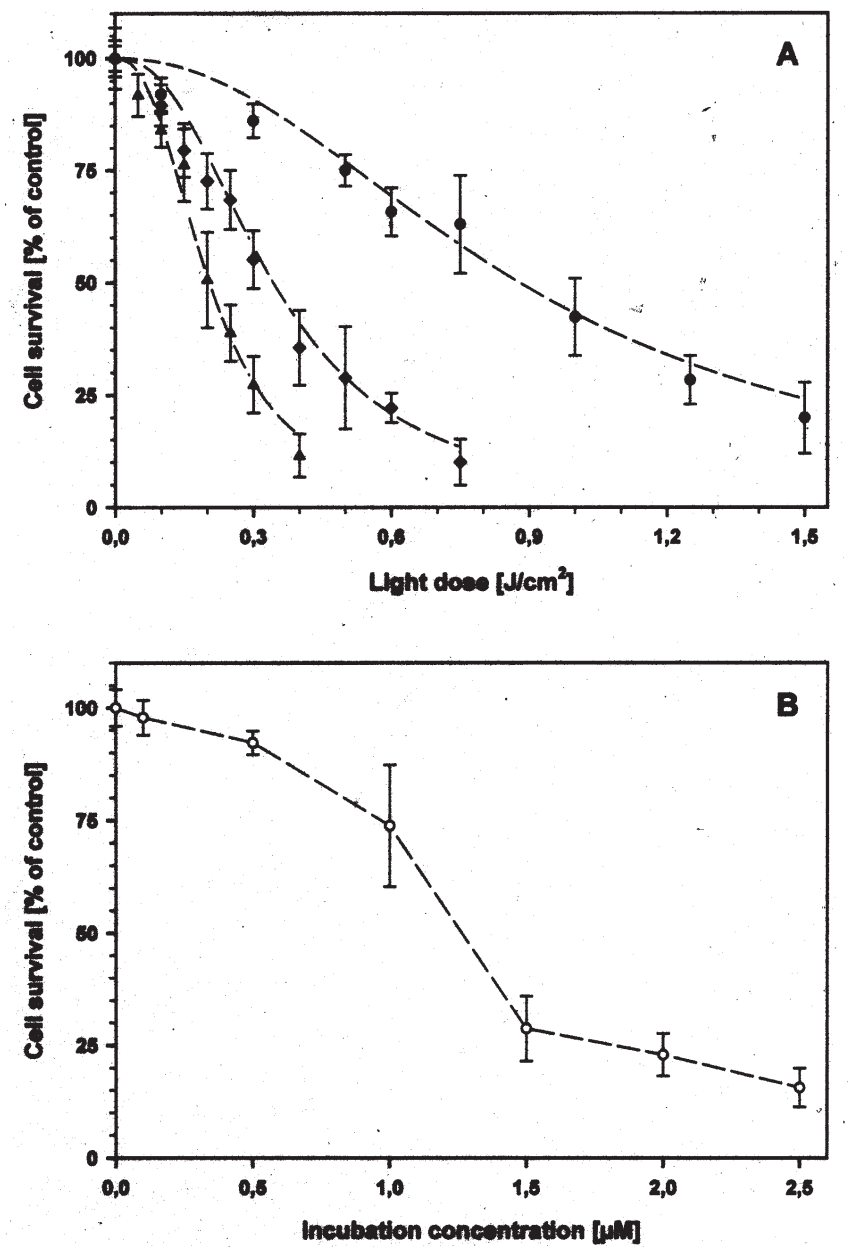

Figure 3. Phototoxicity of HYP in (A) T98G [0.5 $\mu \mathrm{M}(\bullet), 1.5 \mu \mathrm{M}(\bullet)$ and $2.5 \mu \mathrm{M}(\mathbf{\Delta})]$ and (B) U373 MG human glioblastoma cells dependent on incubation concentration (incubation time of $2 \mathrm{~h}$ ). Illumination was performed at $595 \mathrm{~nm}$ and light was delivered at $5-10 \mathrm{~mW} / \mathrm{cm}^{2}$. Cell viability was determined using the NR-assay $48 \mathrm{~h}$ after illumination. Cell survivals were calculated as percentages of the incubated and non-illuminated controls. Each value represents median \pm MAD of at least three independent experiments performed in quadruplicate.

To determine the optimal wavelength for HY-PDT within cellular environment more precisely, LN229 glioblastoma cells were illuminated at different wavelengths between $575 \mathrm{~nm}$ and $615 \mathrm{~nm}$ in steps of $5 \mathrm{~nm}$; a light dose of $0.3 \mathrm{~J} / \mathrm{cm}^{2}$ was applied at each wavelength after incubation with HY $(2.5 \mu \mathrm{M} / 2 \mathrm{~h})$. Weak to moderate cell inactivation with survival rates decreasing from $90 \%$ to $60 \%$ was observed for wavelengths between $575 \mathrm{~nm}$ and $590 \mathrm{~nm}$. Illumination at $595 \mathrm{~nm}$ and $600 \mathrm{~nm}$ resulted in considerable photodynamic damage of the cells with survival rates of about $20 \%$, respectively. At higher wavelength cell survival increased rapidly and was negligible at wavelengths $>610 \mathrm{~nm}$. These results, i.e. the action spectrum of HY within cellular environment, are shown in Fig. 4.

Intracellular location. Intracellular location of HY was investigated in the three human glioblastoma cell lines U373 MG, LN229 and T98G for non-cytotoxic incubation concentrations of $0.5,1.5$ and $2.5 \mu \mathrm{M}$ (incubation time of $2 \mathrm{~h}$ each) with two different fluorescence microscopic techniques. For all three cell lines, fluorescence of HY upon 


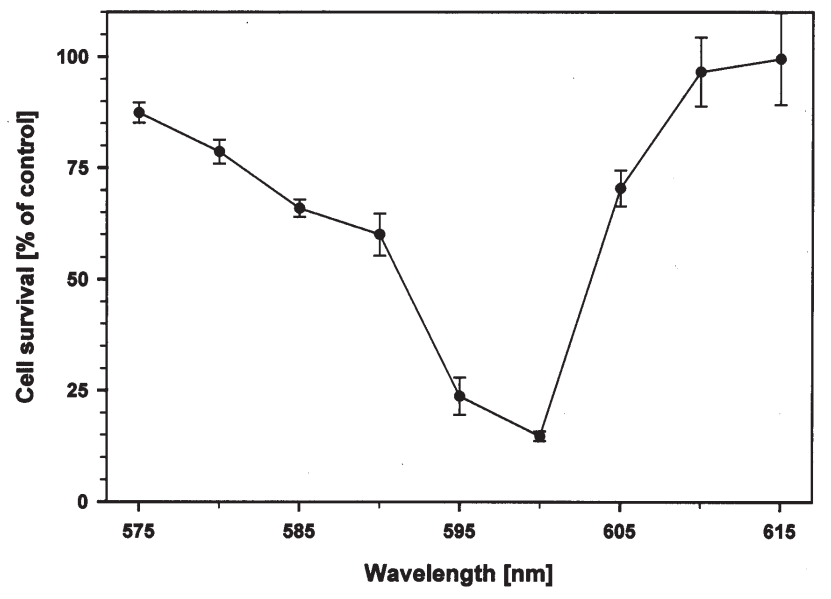

Figure 4. Phototoxicity of HY in human LN229 glioblastoma cells (incubation: $2.5 \mu \mathrm{M}$ for $2 \mathrm{~h})$ after illumination at different wavelengths $\left(0.3 \mathrm{~J} / \mathrm{cm}^{2}\right.$ delivered at $5 \mathrm{~mW} / \mathrm{cm}^{2}$ each). Cell viability was determined using the NR-assay $48 \mathrm{~h}$ after illumination. Cell survivals were calculated as percentages of the incubated and non-illuminated controls. Each value represents median \pm MAD of at least three independent experiments performed in quadruplicate.

epi-illumination (i.e. conventional fluorescence microscopy) arose predominantly from the perinuclear region (typically on one side of the nucleus with some small granules) and the nuclear membrane. In addition, faint fluorescence was detected within the whole cytoplasm. As depicted in Fig. 5 [A1 (U373 MG), B1 (T98G) and C1 (LN229)], no obvious differences in intracellular location were observed for the three glioblastoma cell lines incubated at a HY concentration of $2.5 \mu \mathrm{M}$. Moreover, intracellular distribution of HY remained basically unchanged when the incubation concentration of $\mathrm{HY}$ was reduced to $1.5 \mu \mathrm{M}$ and $0.5 \mu \mathrm{M}$ as exemplarily shown for T98G cells [Fig. 5, B1 $(2.5 \mu \mathrm{M})$, B2 $(1.5 \mu \mathrm{M})$ and B3 $(0.5 \mu \mathrm{M})]$, although fluorescence intensity decreased with decreasing HY supply. In all cases, cell borders have been visible suggesting that HY was also located in the plasma membrane of the glioblastoma cells.

Therefore, total internal reflection fluorescence microscopy (TIRFM) was applied. This microscopic technique enables a quite selective excitation of fluorophores in (or in close vicinity to) the plasma membrane, since the penetration depth $d(\Theta)$ of the excitation light is limited (see above). For all three cell lines, HY fluorescence could be easily detected upon TIR illumination as exemplarily shown for LN229 cells [Fig. 5, C2 $\left(\mathrm{d}(\Theta) \approx 150 \mathrm{~nm}\right.$ at $\left.\Theta=66^{\circ}\right)$ and $\mathrm{C} 3(\mathrm{~d}(\Theta)$ $\approx 80 \mathrm{~nm}$ at $\left.\left.\Theta=70^{\circ}\right)\right]$. In all cases, fluorescence images upon TIR illumination showed some structured pattern with highest intensity in those sites where the plasma membrane is in immediate vicinity to the glass substrate.

Staining of the three glioblastoma cell lines with the mitochondrial marker rhodamine 123 (R123) and the lyosomal marker acridine orange (AO) resulted in fluorescence patterns which have been distinctly different from those observed after HY incubation as shown for U373 MG cells [Fig. 5, A1 (HY), A2 (R123) and A3 (AO)]. Therefore, mitochondria and lysosomes seem to be not the predominant location sites of HY within these glioblastoma cells.

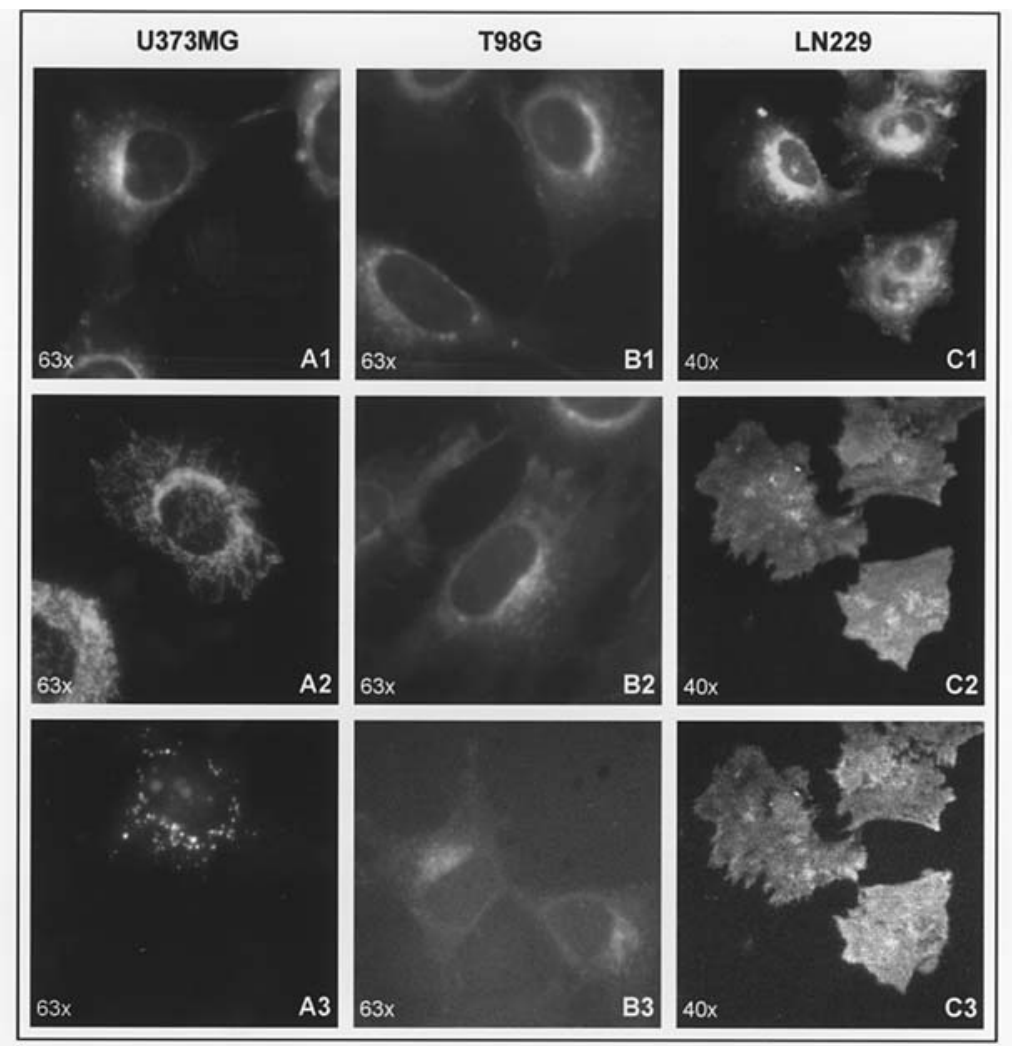

Figure 5. Fluorescence microscopic images of U373 MG, T98G and LN229 glioblastoma cells; U373 MG cells incubated with HY (2.5 $\mu$ M/2 h, A1), rhodamine $123(1 \mu \mathrm{M} / 1 \mathrm{~h} ; \mathrm{A} 2)$ and acridine orange $(1 \mu \mathrm{M} / 1 \mathrm{~h}, \mathrm{~A} 3)$; T98G cells incubated with $\mathrm{HY}$ at concentrations of $2.5 \mu \mathrm{M}(\mathrm{B} 1)$, $1.5 \mu \mathrm{M}(\mathrm{B} 2)$ and $0.5 \mu \mathrm{M}$ (B3) for $2 \mathrm{~h}$ each; LN229 cells incubated with $\mathrm{HY}(2.5 \mu \mathrm{M} / 2 \mathrm{~h})$ upon epi-illumination $(\mathrm{C} 1)$ and TIR illumination $\left(\mathrm{C} 2 / \Theta=66^{\circ}\right.$ and $\mathrm{C} 3 / \Theta=70^{\circ}$ with $\Theta$ corresponding to the angle of incidence). Fluorescence was measured at $\lambda_{\mathrm{em}}=>590 \mathrm{~nm}$ (HY/acridine orange) or $\lambda_{\mathrm{em}}=>520 \mathrm{~nm}$ (rhodamine 123 ). 


\section{Discussion}

For all three glioblastoma cell lines, HY exhibited high phototoxicity combined with weak to negligible cytotoxicity of the compound itself (dark toxicity). Illumination of HYtreated glioblastoma cells $(2 \mathrm{~h} / 2.5 \mu \mathrm{M})$ at $595 \mathrm{~nm}$ with light doses as low as $0.15-0.20 \mathrm{~J} / \mathrm{cm}^{2}$ resulted in a decrease in cell survival to $50 \%$ ( ID $_{50}$-values); after exposure to $0.4 \mathrm{~J} / \mathrm{cm}^{2}$ cell survival was reduced to about $10 \%$ as compared to nonilluminated controls. These results are basically in line with results obtained for other cell lines $(11,13,16)$. In the case of AY-27 cells (transitional cell carcinoma), incubated with HY $(0.05-10 \mu \mathrm{M} / 2 \mathrm{~h})$ and illuminated $(595 \mathrm{~nm})$ of under quite similar experimental conditions as used in the present study, an incubation concentration of about $2.5 \mu \mathrm{M}$ was required to reduced cell survival to $50 \%\left(\mathrm{IC}_{50}\right.$-value $)$ when cells were illuminated with $0.45 \mathrm{~J} / \mathrm{cm}^{2}$ (12). Another study, which compared the sensitivity of four different cell lines to HY-PDT, cell survival could be decreased to about $50 \%$ with incubation concentrations of $1.25 \mu \mathrm{M}$ and $2.5 \mu \mathrm{M}$ (incubated for $5 \mathrm{~h}$ ) and light exposure to $0.4 \mathrm{~J} / \mathrm{cm}^{2}$ (11). Finally, sensitivity of U373 MG cells to HY-PDT seem to be somewhat higher as compared to that of the two other cell lines. This might be caused by an increased uptake of HY in U373 MG or (and) an increased sensitivity of this cell line to oxidative stress. As demonstrated previously, photodynamic efficacy of HY varied between different cell lines, and was directly related to the intracellular accumulation of the photosensitizer (10).

As exemplified for LN229 glioblastoma cells (Fig. 4), efficient photodynamic cell inactivation could also be achieved at wavelength slightly $>595 \mathrm{~nm}$; considering the experimental protocol of the present study, i.e. illumination at wavelength from $575 \mathrm{~nm}$ to $615 \mathrm{~nm}$ in steps of $5 \mathrm{~nm}$, an optimal wavelength of $600 \mathrm{~nm}$ for HY-PDT was determined. This is basically in agreement with previous results obtained with RT-112 (human transitional cell carcinoma), where illuminations at 592, 595 and $598 \mathrm{~nm}$ resulted in almost identical cell survival (36). However, it should be mentioned that the surviving fractions of RT-112 cells were very small (far below 10\%), which usually compromises the reliability of data on cell survival obtained by an optical test. In addition, it has been demonstrated in vivo (C26 colon carcinoma cells inoculated subcutaneously) that HY-PDT was more effective at $590 \mathrm{~nm}$ as compared to that at $550 \mathrm{~nm}$. This was deduced from an increase in the depth of tumour necrosis, which was not solely due to the increased penetration depth of yellow light as compared to green light (13).

Cellular accumulation of $\mathrm{HY}$ in U373 MG glioblastoma cells was determined in a time- and concentration-dependent manner by flow cytometry. Maximum intracellular HY fluorescence was achieved after an incubation time of about $2 \mathrm{~h}$ and incubation concentrations greater than $5 \mu \mathrm{M}$ (Fig. 1). These findings are concordant with a fluorescence microscopic study reported by us recently (33), where 20 different glioma cells ( 8 permanent cell lines and 12 primary cultures) exhibited maximum fluorescence at $1-2 \mathrm{~h}$ after incubation with HY at a concentration of $20 \mu \mathrm{M}$. Although similar fluorescence intensities were found after 24-h incubation with $\mathrm{HY}$ at concentrations of 2.5 and $20 \mu \mathrm{M}$, accumulation kinetics of HY in U373 MG cells seem to differ considerably.
However, it should be mentioned that reliability of fluorescence measurements will be compromised when the fluorescence quantum yield of the chromophore changes, e.g. in cellular environment. For PAM-212 cells (murine keratinocytes) incubated with $\mathrm{HY}$ at concentrations as high as $50 \mu \mathrm{M}$, the intracellular formation of weakly fluorescent aggregates has been supposed (37). Incubation of U373 MG glioblastoma cells at a concentration of $2.5 \mu \mathrm{M}$ resulted in an almost linear increase in intracellular HY fluorescence up to an incubation time of $4 \mathrm{~h}$ (Fig. 2), which increased further with increasing incubation time (Fig. 1). Again, these data are basically in line with previous results obtained for other cell lines $(10,11)$.

Since contradictory results concerning the cellular uptake mechanism of HY have been published $(16,38)$, this issue was addressed in some more detail. No increase in cellular HY accumulation was observed in U373 MG glioblastoma cells after 2 -h incubation at $4^{\circ} \mathrm{C}$ (Fig. 2). Since cellular metabolism is severely impaired at low temperatures, these data strongly indicate that $\mathrm{HY}$ is taken up into this cell line by an energy-dependent process, e.g. by receptor-mediated endocytosis or pinocytosis, rather than by (passive) diffusion. In contrast, no noticeable difference in the HY staining pattern in WiDr cells (human colon carcinoma cell line) was found when comparing fluorescence images after $1 \mathrm{~h}$ incubation at $4^{\circ} \mathrm{C}$ or at room temperature by Uzdensky et al (16). Consequently, they concluded that HY penetrates cells mostly by diffusion. Although the uptake mechanism of HY in cells of different origin might vary, it should be stressed that is virtually essential to inhibit energy metabolism early enough prior to cell incubation, e.g. reversibly by pre-cooling of cells and media as described above. However, an active uptake of HY in cells is basically in agreement with data obtained with Caco-2 cell monolayers, a model system to investigate intestinal absorption. Transcellular transport of $\mathrm{HY}$ at $4^{\circ} \mathrm{C}$ was significantly lower than at $37^{\circ} \mathrm{C}$. Concomitantly, binding studies of $\mathrm{HY}$ to $\mathrm{Caco}-2$ cells revealed a relatively low affinity constant (about $0.1 \mathrm{mM}$ ). Taken together, these data obtained for Caco-2 cells under serum free conditions suggest that HY is actively taken up after non-specific binding to membrane lipids (38). In addition, alteration of individual steps of endocytosis and membrane cycling changed the intracellular HY location (39), which also indicate the involvement of energy-dependent processes in uptake and distribution of HY in living cells .

Comparison of the fluorescence pattern observed for HY with that found for the two organelle markers, revealed that neither mitochondria nor lysosomes are the primary location sites of the photosensitizer. For all three glioblastoma cell lines, intracellular distribution of HY was quite similar and not affected by its incubation concentration. HY fluorescence was detected predominantly in the perinuclear region and the nuclear membrane. Thus, in agreement with previous localisation studies $(16,40,41)$, it is supposed that HY localises preferentially within the membranes of the endoplasmic reticulum and the Golgi complex. However, it should be mentioned that location of HY in mitochondria and lysosomes has been also supposed for other cell lines $(11,42)$.

Concerning the location of HY within the plasma membrane, also contradictory results obtained by confocal 
fluorescence microscopy have been published (16,38). In the present study, total internal reflection fluorescence microscopy (TIRFM) was used to address this issue. Excitation of fluorophors is carried out by an evanescent field with a penetration depth of about $100 \mathrm{~nm}$ depending preferentially on the angle of incidence. Thus, this microscopic technique is virtually unique with respect to its axial resolution in close vicinity to the cell-substrate interface. HY fluorescence could be detected with TIRFM even at penetration depths below $100 \mathrm{~nm}$, where the contribution of intracellular fluorophors is almost negligible. Thus, HY location in (and/or immediate vicinity to) the plasma membrane can be considered as proven for all three glioblastoma cell lines.

Due to the hydrophobicity of HY, serum proteins are necessary to deliver the photosensitizer to the cells; alternatively, solubilizers, e.g. cyclodextrins or liposomes (38), were essential under serum free conditions. Since cellular accumulation of HY seem to be crucially affected by the composition of the cell culture medium $(15,38,42)$, comparability of the results of the individual studies is hampered.

HY is preferentially bound to low-density lipoproteins (LDL) and smaller fractions are associated with high-density lipoproteins or very low-density lipoproteins as shown with density-gradient ultracentifugation (41) and spectroscopic methods $(41,43)$. However, interaction with albumin has also been shown $(41,44)$. Binding of HY to LDL might suggest that one reasonable active uptake mechanism of this photosensitizer in tumour cells is LDL-receptor-mediated endocytosis, as supposed previously also for porphyrin-based photosensitizers (1). This hypothesis may in particular hold for glioblastoma cells, which have very high numbers (several hundreds of thousands per cell) of LDL receptors (45). Cellular uptake via LDL receptor-mediated endocytosis is directed to the lysosomal compartment for further processing (46). However, fluorescence microscopy revealed that lysosomes seem not to be the primary location site of HY in glioblastoma cells after $2 \mathrm{~h}$ incubation (Fig. 5).

Due to a very short lifetime, diffusion length of singletoxygen is limited to a few tens of nanometers in cellular environment (47). Therefore, close proximity between location and damage site of the photosensitizer is required. Although accumulation of HY in mitochondria was not found in any of the three glioblastoma cells studied (see above), there is sufficient evidence in literature that mitochondria are primary cellular damage sites of HY-PDT $(11,48-50)$. Thus, an ultraweak amount of HY seem to be sufficient for light-induced mitochondrial damage initiating apoptotic cell death. This has been demonstrated for numerous cell lines, including glioblastoma cells, as reviewed by Agostinis et al (5). Location of HY in the plasma membrane, as demonstrated in the present study with TIRFM, might induce damage of membrane constituents $(51,52)$ and subsequently necrotic cell death. Finally, it has been shown that the ratio between apoptotic and necrotic cell death induced by HY-PDT depends on drug and light dose, and probably also on the genetic background of the cell line (5).

In conclusion, the present study demonstrates that glioblastoma cells can be effectively inactivated by HY-PDT after short-time incubation and exposure to low light doses. Due to its lipophilicity, HY seems to be preferentially located in cellular membranes, including the plasma membrane. In addition to its low cytotoxicity (in the dark), HY has biological properties, such as inhibition of cell proliferation and signal transduction $(53,54)$, which might be of additional advantage for the treatment of malignant glioma. These results obtained in cell culture are encouraging and justify further evaluation of HY-PDT for the treatment of malignant glioma in animal experiments.

\section{Acknowledgments}

The authors especially appreciate the cooperation in fluorescence microscopy of Professor Herbert Schneckenburger and Dipl.-Ing. (FH) Michael Wagner, Institut für Angewandte Forschung, Hochschule Aalen, Germany. Technical assistance by Petra Kruse and Eva Winkler, Institut für Lasertechnologien in der Medizin und Messtechnik an der Universität Ulm, Ulm, Germany, is gratefully acknowledged.

\section{References}

1. Dougherty T, Gomer C, Henderson B, Jori G, Kessel D, Korbelik M, Moan J and Peng Q: Photodynamic therapy. J Natl Cancer Inst 90: 889-905, 1998.

2. Tang J, Colacino JM, Larsen SH and Spitzer W: Virucidal activity of hypericin against enveloped and non-enveloped DNA and RNA viruses. Antiviral Res 13: 313-325, 1990.

3. Gupta V, Su Y, Wang W, Kardosh A, Liebes L, Hofman F, Schonthal A and Chen TC: Enhancement of glioblastoma cell killing by combination treatment with temozolomide and tamoxifen or hypericin. Neurosurg Focus 20: E20, 2006.

4. Martinez-Poveda B, Quesada AR and Medina MA. Hypericin in the dark inhibits key steps of angiogenesis in vitro. Eur $\mathrm{J}$ Pharmacol 516: 97-103, 2005.

5. Agostinis P, Vantieghem A, Merlevede W and De Witte PA: Hypericin in cancer treatment: more light on the way. Int $\mathbf{J}$ Biochem Cell Biol 34: 221-241, 2002.

6. Diwu Z and Lown JW: Photosensitization with anticancer agents. EPR studies of photodynamic action of hypericin: formation of semiquinone radical and activated oxygen species on illumination. Free Radic Biol Med 14: 209-215, 1993.

7. Ehrenberg B, Anderson JL and Foote CS: Kinetics and yield of singlet oxygen photosensitized by hypericin in organic and biological media. Photochem Photobiol 68: 135-140, 1998.

8. Hadjur C, Richard MJ, Parat MO, Favier A and Jardon P: Photodynamically induced cytotoxicity of hypericin dye on human fibroblast cell line MRC5. J Photochem Photobiol B 27: 139-146, 1995.

9. Thomas $C$ and Pardini RS: Oxygen dependence of hypericininduced phototoxicity to EMT6 mouse mammary carcinoma cells. Photochem Photobiol 55: 831-837, 1992.

10. Vandenbogaerde AL, Cuveele JF, Proot P, Himpens BE, Merlevede WJ and De Witte PA: Differential cytotoxic effects induced after photosensitization by hypericin. J Photochem Photobiol B 38: 136-142, 1997.

11. Ali SM and Olivo M: Bio-distribution and subcellular localization of Hypericin and its role in PDT induced apoptosis in cancer cells. Int J Oncol 21: 531-540, 2002.

12. Kamuhabwa AR, Agostinis PM, D'Hallewin MA, Baert L and De Witte PA: Cellular photodestruction induced by hypericin in AY-27 rat bladder carcinoma cells. Photochem Photobiol 74: 126-132, 2001.

13. Blank M, Kostenich G, Lavie G, Kimel S, Keisari Y, and Orenstein A: Wavelength-dependent properties of photodynamic therapy using hypericin in vitro and in an animal model. Photochem Photobiol 76: 335-340, 2002.

14. Liu CD, Kwan D, Saxton RE and McFadden DW: Hypericin and photodynamic therapy decreases human pancreatic cancer in vitro and in vivo. J Surg Res 93: 137-143, 2000.

15. Kamuhabwa AR, Agostinis P, D'Hallewin MA, Kasran A and De Witte PA: Photodynamic activity of hypericin in human urinary bladder carcinoma cells. Anticancer Res 20: 2579-2584, 2000 . 
16. Uzdensky AB, Ma LW, Iani V, Hjortland GO, Steen HB and Moan J: Intracellular localisation of hypericin in human glioblastoma and carcinoma cell lines. Lasers Med Sci 16: 276-283, 2001.

17. Couldwell WT, Gopalakrishna R, Hinton DR, He S, Weiss MH, Law RE, Apuzzo ML and Law RE: Hypericin: a potential antiglioma therapy. Neurosurgery 35: 705-709, 1994.

18. Ohgaki H, Dessen P, Jourde B, Horstmann S, Nishikawa T, Di Patre PL, Burkhard C, Schuler D, Probst-Hensch NM, Maiorka PC, Baeza N, Pisani P, Yonekawa Y, Yasargil MG, Lutolf UM and Kleihues P: Genetic pathways to glioblastoma: a population-based study. Cancer Res 64: 6892-6899, 2004.

19. Stupp R, Mason WP, van den Bent MJ, Weller M, Fisher B, Taphoorn MJ, Belanger K, Brandes AA, Marosi C, Bogdahn U, Curschmann J, Janzer RC, Ludwin SK, Gorlia T, Allgeier A, Lacombe D, Cairncross JG, Eisenhauer E and Mirimanoff RO: Radiotherapy plus concomitant and adjuvant temozolomide for glioblastoma. N Engl J Med 352: 987-996, 2005.

20. Bashir R, Hochberg F and Oot R: Regrowth patterns of glioblastoma multiforme related to planning of interstitial brachytherapy radiation fields. Neurosurgery 23: 27-30, 1988.

21. Stummer W, Novotny A, Stepp H, Goetz C, Bise K and Reulen HJ: Fluorescence-guided resection of glioblastoma multiforme by using 5 -aminolevulinic acid-induced porphyrins: a prospective study in 52 consecutive patients. J Neurosurg 93: 1003-1013, 2000.

22. Stummer W, Pichlmeier U, Meinel T, Wiestler O, Zanella F, Reulen HJ and ALA-Glioma Study Group: Fluorescence-guided surgery with 5-aminolevulinic acid for resection of malignant glioma: a randomised controlled multicentre phase III trial. Lancet Oncol 7: 392-401, 2006.

23. Duffner F, Ritz R, Freudenstein D, Weller M, Dietz K and Wessels J: Specific intensity imaging for glioblastoma and neural cell cultures with 5-aminolevulinic acid-derived protoporphyrin IX. J Neurooncol 71: 107-111, 2005.

24. Wu S, Ren Q, Zhou M, Peng Q and Chen J: Protoporphyrin IX production and its photodynamic effects on glioma cells, neuroblastoma cells and normal cerebellar granule cells in vitro with 5-aminolevulinic acid and its hexyleste. Cancer Lett 200: 123-131, 2003.

25. Stummer W, Stocker S, Novotny A, Heimann A, Sauer O, Kempsk O, Plesnila N, Wietzorrek J and Reulen HJ: In vitro and in vivo porphyrin accumulation by C6 glioma cells after exposure to 5-aminolevulinic acid. J Photochem Photobiol B 45: 160-169, 1998.

26. Hebeda K, Saarnak A, Olivo M, Sterenborg H and Wolbers JG: 5-Aminolevulinic acid induced endogenous fluorescence in 9L and c6 brain tumours and in normal rat brain. Acta Neurochir 140: 503-512, 1998.

27. Hirschberg H, Sun C-H, Tromberg BJ and Madsen S: ALA- and ALA-esters-mediated phototdynamic therapy of human glioma spheroids. J Neurooncol 57: 1-7, 2002.

28. Madsen SJ, Sun CH, Tromberg BJ, Wallace VP and Hirschberg H: Photodynamic therapy of human glioma spheroids using 5-aminolevulinic acid. Photochem Photobiol 72: 128-134, 2000 .

29. Angell-Petersen E, Spetalen S, Madsen S, Sun C, Peng Q, Carper S, Sioud M and Hirschberg H: Influence of light fluence rate on the effects of photodynamic therapy in an orthopic rat glioma model. J Neurosurg 104: 109-117, 2006.

30. Hirschberg H, Sorensen D, Angell-Petersen E, Peng Q, Tromberg B, Sun C, Spetalen S and Madsen S: Repetive photodynamic therapy of malignant brain tumors. J Environ Pathol Toxicol Oncol 25: 261-280, 2006

31. Ito S, Rachinger W, Stepp H, Reulen HJ and Stummer W: Oedema formation in experimental photo-irradiation of brain tumors using 5-ALA. Acta Neurochir 147: 57-65, 2005.

32. Olzowy B, Hundt C, Stocker S, Bise K, Reulen HJ and Stummer W: Photoirradiation therapy of experimental malignant glioma with 5-aminolevulinic acid. J Neurosurg 97: 970-976, 2002.

33. Ritz R, Müller M, Weller M, Dietz K, Kuci S, Roser F and Tatagiba M: Hypericin: a promising fluorescence marker for differentiating between glioblastoma and neurons in vitro. Int J Oncol 27: 1543-1549, 2005.

34. Fautrel A, Chesné C, Guillouzo A, De Sousa G, Placidi M, Rahmani R, Braut F, Pichon J, Hoellinger H, Vintézou P, Diarte I, Melcion C, Cordier A, Lorenzon G, Benicourt M, Vannier B, Fournex R, Peloux AF, Bichet N, Gouy D, Cano JP and Lounes R: A multicentre study of acute in vitro cytotoxicity in rat liver cells. Toxicol in Vitro 5: 543-547, 1991.
35. Stock K, Sailer R, Strauss W, Lyttek M, Steiner R and Schneckenburger H: Variable-angle total internal reflection fluorescence microscopy (VA-TIRFM); realization and application of a compact illumination device. J Microsc 211: 19-29, 2003.

36. Huygens A, Huyghe D, Bormans G, Verbruggen A, Kamuhabwa AR, Roskams T and De Witte PA: Accumulation and photocytotoxicity of hypericin and analogs in two- and three-dimensional cultures of transitional cell carcinoma cells. Photochem Photobiol 78: 607-614, 2003.

37. Theodossiou T, Spiro MD, Jacobson J, Hothersall JS and Macrobert AJ: Evidence for intracellular aggregation of hypericin and the impact on its photocytotoxicity in PAM 212 murine keratinocytes. Photochem Photobiol 80: 438-443, 2004.

38. Sattler S, Schaefer U, Schneider W, Hoelzl J and Lehr CM: Binding, uptake, and transport of hypericin by Caco-2 cell monolayers. J Pharm Sci 86: 1120-1126, 1997.

39. Weber ND, Murray BK, North JA and Wood SG: The antiviral agent hypericin has in vitro activity against HSV-1 through non-specific association with viral and cellular membranes. Antiviral Chem Chemother 5: 83-90, 1994.

40. Vandenbogaerde AL, Delaey EM, Vantieghem AM, Himpens BE, Merlevede WJ and De Witte PA: Cytotoxicity and antiproliferative effect of hypericin and derivatives after photosensitization. Photochem Photobiol 67: 119-125, 1998.

41. Delaey EM, Obermueller R, Zupko I, De Vos D, Falk H and De Witte PA: In vitro study of the photocytotoxicity of some hypericin analogs on different cell lines. Photochem Photobiol 74: 164-171, 2001.

42. Siboni G, Weitman H, Freeman D, Mazur Y, Malik Z and Ehrenberg B: The correlation between hydrophilicity of hypericins and helianthrone: internalization mechanisms, subcellular distribution and photodynamic action in colon carcinoma cells. Photochem Photobiol Sci 1: 483-491, 2002.

43. Kascakova S, Refregiers M, Jancura D, Sureau F, Maurizot JC and Miskovsky P: Fluorescence spectroscopic study of hypericinphotosensitized hxidation of how-density hipoproteins. Photochem Photobiol 81: 1395-1403, 2005.

44. Miskovsky P, Hritz J, Sanchez-Cortes S, Fabriciova G, Ulicny J and Chinsky L: Interaction of hypericin with serum albumins: surface-enhanced Raman spectroscopy, resonance Raman spectroscopy and molecular modeling study. Photochem Photobiol 74: 172-183, 2001

45. Maletinska L, Blakely EA, Bjornstad KA, Deen DF, Knoff LJ and Forte TM: Human glioblastoma cell lines: levels of lowdensity lipoprotein receptor and low-density lipoprotein receptorrelated protein. Cancer Res 60: 2300-2303, 2000.

46. Li Y, Cam J and Bu G: Low-density lipoprotein receptor family: endocytosis and signal traduction. Mol Neurobiol 23: 53-67, 2001.

47. Moan J and Berg K: The photodegradation of porphyrins in cells can be used to estimate the lifetime of singlet oxygen. Photochem Photobiol 53: 549-553, 1991.

48. Miccoli L, Beurdeley-Thomas A, De Pinieux G, Sureau F, Oudard S, Dutrillaux B and Poupon MF: Light-induced photoactivation of hypericin affects the energy metabolism of human glioma cells by inhibiting hexokinase bound to mitochondria. Cancer Res 58: 5777-5786, 1998.

49. Johnson SA and Pardini RS: Antioxidant enzyme response to hypericin in EMT6 mouse mammary carcinoma cells. Free Radic Biol Med 24: 817-826, 1998.

50. Theodossiou T, Noronha-Dutra A and Hothersall JS: Mitochondria are a primary target of hypericin phototoxicity: synergy of intracellular calcium mobilsation in cell killing. Int J Biochem Cell Biol 38: 1946-1956, 2006.

51. Hadjur C, Richard MJ, Parat MO, Jardon P and Favier A: Photodynamic effects of hypericin on lipid peroxidation and antioxidant status in melanoma cells. Photochem Photobiol 64: 375-381, 1996.

52. Chaloupka R, Obsil T, Plasek J and Sureau F: The effect of hypericin and hypocrellin-A on lipid membranes and membrane potential of 3T3 fibroblasts. Biochim Biophys Acta 1418: 39-47, 1999.

53. Zhang W, Law RE, Hinton DR and Couldwell WT: Inhibition of human malignant glioma cell motility and invasion in vitro by hypericin, a potent protein kinase $\mathrm{C}$ inhibitor. Cancer Lett 120: 31-38, 1997.

54. Blank M, Lavie G, Mandel M, Hazan S, Orenstein A, Meruelo D and Keisari Y: Antimetastatic activity of the photodynamic agent hypericin in the dark. Int J Cancer 111: 596-603, 2004. 